\title{
Gordonibacter pamelaeae gen. nov., sp. nov., a new member of the Coriobacteriaceae isolated from a patient with Crohn's disease, and reclassification of Eggerthella hongkongensis Lau et al. 2006 as Paraeggerthella hongkongensis gen. nov., comb. nov.
}

Correspondence

Dieco Würdemann dieco.wuerdemann @helmholtz-hzi.de
Dieco Würdemann, ${ }^{1}$ Brian J. Tindall, ${ }^{2}$ Rüdiger Pukall, ${ }^{2}$ Heinrich Lünsdorf, ${ }^{3}$ Carsten Strömpl, ${ }^{1}$ Theresa Namuth, ${ }^{1}$ Hannes Nahrstedt, ${ }^{4}$ Melissa Wos-Oxley, ${ }^{4}$ Stephan Ott, ${ }^{5}$ Stephan Schreiber, ${ }^{5}$ Kenneth N. Timmis ${ }^{1}$ and Andrew P. A. Oxley ${ }^{1}$

\footnotetext{
${ }^{1}$ Environmental Microbiology Laboratory, Helmholtz Centre for Infection Research, Inhoffenstr. 7, D-38124 Braunschweig, Germany

${ }^{2}$ DSMZ - German Collection of Microorganisms and Cell Cultures, Inhoffenstr. 7B, D-38124 Braunschweig, Germany

${ }^{3}$ Department of Vaccinology, Helmholtz Centre for Infection Research, Inhoffenstr. 7, D-38124 Braunschweig, Germany

${ }^{4}$ Biodegradation Group, Helmholtz Centre for Infection Research, Inhoffenstr. 7, D-38124 Braunschweig, Germany

${ }^{5}$ Institute for Clinical Molecular Biology, Christian-Albrechts-University Kiel, Schittenhelmstr. 12, D-24105 Kiel, Germany
}

A strictly anaerobic, Gram-positive, short-rod/coccobacillus-shaped bacterial strain, designated $7-10-1-b^{\top}$, was isolated from the colon of a patient suffering from acute Crohn's disease. The isolate formed small, pale-white, semi-translucent colonies on solid cultivation media. The strain was catalase-positive and metabolized only a small number of carbon sources. Whole-cell fatty acids consisted predominantly of saturated fatty acids (89\%), of which 15:0 anteiso was the major component. The polar lipids phosphatidylglycerol and diphosphatidylglycerol as well as four glycolipids were identified. 16S rRNA gene sequence analysis revealed that the isolate represents a distinct lineage within the family Coriobacteriaceae and has $94.6 \%$ identity to the type strain of [Eggerthella] hongkongensis, the phylogenetically closest bacterial species. On the basis of the analyses performed, the new genus and species Gordonibacter pamelaeae gen. nov., sp. nov. is described, with strain 7-10-1- $\mathrm{b}^{\top}$ (=DSM $19378^{\top}=$ CCUG $\left.55131^{\top}\right)$ as the type and only strain of Gordonibacter pamelaeae. Also, based on the chemotaxonomic data obtained for all type strains of the neighbouring genus Eggerthella, we propose that Eggerthella hongkongensis Lau et al. 2006 be transferred to a new genus as Paraeggerthella hongkongensis gen. nov., comb. nov.; the type strain of Paraeggerthella hongkongensis is $\mathrm{HKU}_{10} 0^{\top}\left(=\mathrm{DSM} 16106^{\top}=\mathrm{CCUG}_{49250^{\top}}\right)$.

\section{Abbreviation: DMA, dimethylacetal.}

The GenBank/EMBL/DDBJ accession number for the 16S rRNA gene sequence of strain $7-10-1-b^{\top}$ is AM886059.

A dendrogram derived from biochemical profiles, a maximum-likelihood tree based on 16S rRNA gene sequences, TLC of polar lipids of strain 7$10-1-b^{\top}$ and comparisons of the fatty acid and menaquinone profiles of strain $7-10-1-b^{\top}$ and related type strains are available as supplementary material with the online version of this paper.
During a study on the intestinal flora of patients with inflammatory bowel disease (IBD), one isolate from the colon of a patient with acute Crohn's disease showed a unique BOX-PCR fingerprint and subsequently a unique 16S rRNA gene sequence pattern, with 94.6-95.2\% similarity to members of the genus Eggerthella. The genus Eggerthella belongs to the family Coriobacteriaceae, placed within the class Actinobacteria (Wade et al., 1999). 
Members of this genus are anaerobic, non-sporulating, non-motile, Gram-positive bacilli that grow singly, as pairs or in short chains. They are found in the human colon and faeces and have been implicated as a cause of ulcerative colitis, liver and anal abscesses and systemic bacteraemia (Chan \& Mercer, 2008; Landais et al., 2007; Lau et al., 2004a, b). The type species of the genus, Eggerthella lenta, was originally described as 'Bacteroides lentus' (Eggerth, 1935), but was included on the Approved Lists of Bacterial Names in the genus Eubacterium, as Eubacterium lentum.

\section{Growth characteristics}

Strain 7-10-1- $\mathrm{b}^{\mathrm{T}}$ was isolated from the sigmoid region of the colon of a patient with active Crohn's disease (male, age 33, medication Azathioprine + Mutaflor + cortisone) and was obtained by colonoscopy on 30 November 2006 in the Clinic for General Internal Medicine (University-Hospital Schleswig-Holstein, Kiel, Germany). Samples were placed in standard anaerobic transport medium (Port-a-cul tube; BBL) on ice and processed for isolation of bacteria within $24 \mathrm{~h}$. One biopsy specimen was transferred to a microcentrifuge tube with $100 \mu \mathrm{l}$ sterile PBS $(50 \mathrm{mM}$ potassium phosphate, $150 \mathrm{mM} \mathrm{NaCl}, \mathrm{pH}$ 7.2) and homogenized by repeated grinding with a Teflon mortar. The homogenate was diluted further in PBS and aliquots corresponding to $10 \%(1: 10)$ and $1 \%(1: 100)$ of the original biopsy material were plated on a variety of different media. The isolation procedure and incubation of plates was carried out under anaerobic conditions (MACS-VA500 workstation; Meintrup DWS) with an atmosphere consisting of $\mathrm{N}_{2} / \mathrm{H}_{2} / \mathrm{CO}_{2}$ $(80: 10: 10)$ at $37{ }^{\circ} \mathrm{C}$. Plates were monitored for growth and single colonies were subcultivated, checked for purity and screened by BOX-PCR as described previously (Dombek et al., 2000; van Belkum et al., 1996), allowing the differentiation of taxa by targeting highly conserved repetitive DNA elements. One colony (designated here strain 7-10-1- $\left.\mathrm{b}^{\mathrm{T}}\right)$, from a $1: 10$ dilution plated on Schaedler basal agar (Oxoid) supplemented with $5 \%$ defibrinated horse blood, exhibited a unique BOX-PCR profile (data not shown) and was subjected to further investigation using a combination of phenotypic, genotypic and chemotaxonomic methods.

Unless specified otherwise, strain $7-10-1-\mathrm{b}^{\mathrm{T}}$ was cultivated in pre-reduced brain heart infusion (BHI) medium (Oxoid) supplemented with $1 \%$ arginine hydrochloride $(\mathrm{w} / \mathrm{v})$ in Hungate tubes.

Subcultures of strain $7-10-1-\mathrm{b}^{\mathrm{T}}$ occurred as small, palewhite, semi-translucent colonies after 48-72 h of incubation at $37{ }^{\circ} \mathrm{C}$ under strictly anaerobic conditions on agar plates. Growth in liquid media was generally slow, with cells growing to low optical densities (data not shown). Growth could be enhanced with the addition of $1 \%$ arginine hydrochloride $(\mathrm{w} / \mathrm{v})$ (data not shown), which is consistent with the growth requirements of other anaerobic strains isolated from the human colon (Jin et al., 2007). Uematsu et al. (2006) reported on the metabolism of arginine by members of the genera Slackia and Cryptobacterium.

\section{Microscopic and ultrastructural analysis}

For phase-contrast microscopy, mid-exponential and stationary phase cells were visualized under phase-contrast microscopy (Zeiss). Broth cultures of strain $7-10-1-b^{T}$ revealed short-rod/coccobacillus-shaped, motile, nonspore-forming small cells (data not shown).

For electron microscopy, mid-exponential phase cells grown in BHI with and without $1 \%$ arginine hydrochloride were prepared either as whole mounts or as embedded samples and were analysed by energy-filtered transmission electron microscopy as described by Yakimov et al. (1998) and Golyshina et al. (2000).

At the ultrastructural level, as revealed from whole-mount shadow-cast (Fig. 1a, b) and ultrathin-sectioned (Fig. 1c, d) samples, cells appeared rather unusual in morphology. In whole-mount samples, cells grown in BHI appeared flagellated (Fig. 1a; fl) with subpolar flagellum insertion. These short-rod/coccoid cells produced a small amount of slime, which may be seen as a tail-like feature at the cell end. Despite the presence of this slime, the cell wall is clearly outlined (Fig. 1a; cw). Cells grown in BHI supplemented with $1 \%$ arginine hydrochloride, however, were surrounded/encapsulated by a thick amorphous layer of slime, seen as a smooth greyish halo around individual cells or groups of cells (Fig. 1b; sl). These samples also showed cells to have an electron-translucent, massdeficient centre, apparently equivalent to the bacterial chromosome. The mean cell length was $1.01 \pm 0.21 \mu \mathrm{m}$ $(n=35 ; \min =0.64 \mu \mathrm{m} ; \max =1.46 \mu \mathrm{m} ; \operatorname{median}=1.01 \mu \mathrm{m})$ and the mean cell diameter was $509 \pm 55 \mathrm{~nm} \quad(n=49$; $\min =403 \mathrm{~nm}$; $\max =644 \mathrm{~nm}$; median $=507 \mathrm{~nm}$ ). A characteristic feature of whole-mount or ultrathin-sectioned cells was a marked longitudinal asymmetry, with one end of the cell exhibiting a pronounced conical form (Fig. 1a-c; ae). In ultrathin-sectioned cells, the condensed chromosomal DNA is seen in the centre as electron-translucent areas (Fig. 1c, d), surrounded by a rather densely packed cytoplasm. Occasionally, bright inclusions (Fig. 1c; incl) were apparent, probably indicating low-level carbonstorage activity, perhaps as alkanoates, under the growth conditions employed. At higher magnification, the cell-wall architecture is typical of a classical Gram-positive cell wall. An outer murein layer of mean thickness $12.8 \pm 0.9 \mathrm{~nm}$ $(n=25 ; \min =10.8 \mathrm{~nm} ; \max =14.7 \mathrm{~nm} ; \operatorname{median}=12.8 \mathrm{~nm})$ was in direct contact with the cytoplasmic membrane (mean thickness $=7.6 \pm 1.1 \mathrm{~nm} ; n=43 ; \quad \min =4.6 \mathrm{~nm}$; $\max =9.6 \mathrm{~nm}$; median $=7.7 \mathrm{~nm}$ ).

\section{Phenotypic characterization}

The type strains of all three currently recognized species of the genus Eggerthella (E. lenta DSM 2243 ${ }^{\mathrm{T}}$, [Eggerthella] hongkongensis DSM $16106^{\mathrm{T}}$ and Eggerthella sinensis DSM 

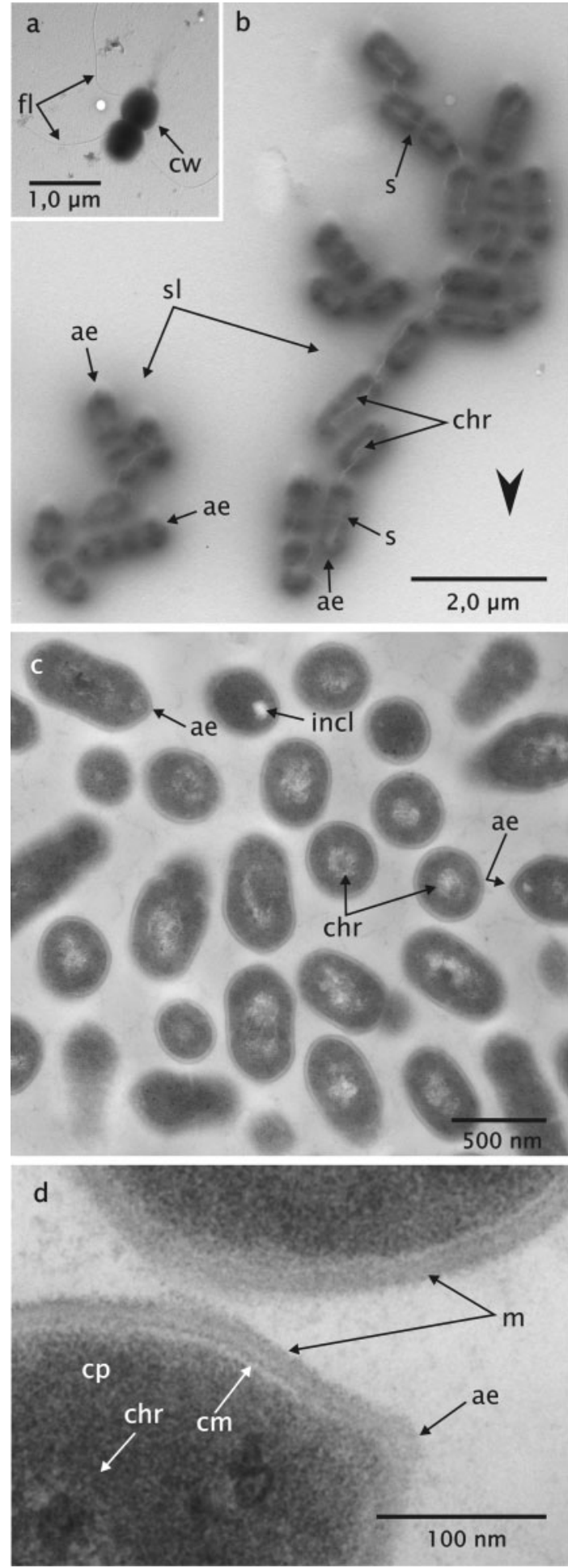

$16107^{\mathrm{T}}$ ) were obtained from the DSMZ for comparative analyses and were resuscitated and maintained under the conditions specified in the DSMZ online catalogue (http:// www.dsmz.de).

Routine tests (such as Gram stain and catalase activity) were carried out using standard protocols (Doetsch, 1981;
Fig. 1. Ultrastructure of cells of strain $7-10-1-b^{\top}$. (a) Wholemount preparation of $\mathrm{Pt}-\mathrm{C}$ shadow-cast cells grown in $\mathrm{BHI}$. Subpolarly inserted flagella (fl) are present and the cell-wall surface (cw) can be recognized. (b) Air-dried cells grown in BHI supplemented with $1 \%$ arginine hydrochloride are surrounded by a smooth halo of slime (sl). The chromosomal area (chr) appears translucent, surrounded by the dense cytoplasm; septum formation (s) is shown with dividing cells. The arrowhead indicates the direction of shadowing. (c, d) Ultrathin-sectioned cells, which appear translucent in the chromosomal area, surrounded by a densely packed cytoplasm. Often one cell end appears conical in shape with a pronounced apex-ending (ae); the cytoplasmic membrane $(\mathrm{cm})$ is layered by a characteristic murein layer $(\mathrm{m})$. incl, Cytoplasmic inclusion.

McCarthy \& Cross, 1984). Additional physiological tests were performed using the API Rapid ID32A and API 20A kits (bioMérieux). Conversion of a variety of different carbon sources was examined using the AN MicroPlate system (an anaerobe identification test panel) following the manufacturer's instructions (Biolog).

The biochemical characteristics of strain $7-10-1-b^{\mathrm{T}}$ and the Eggerthella type strains are summarized in Table 1. Strain 7-10-1- $\mathrm{b}^{\mathrm{T}}$ was Gram-positive and catalase-positive, but generally negative for utilization of most substrates. Only one positive reaction (arginine dihydrolase) was observed with the API kits, the only test that gave a positive reaction for all strains used in the comparison. In addition, only six carbon sources, L-methionine, L-phenylalanine, L-valine, Lvaline plus L-aspartic acid, dextrin and D-glucose 6phosphate, were metabolized in Biolog plates. Weak reactions were observed for pyruvic acid and pyruvic acid methyl ester.

Parsimony analysis of phenotypic data presented in Table 1 was performed with the program PARS (PHYLIP package, version 3.66; Felsenstein, 1989), where positive reactions were defined as 1 and negative or variable reactions declared as 0 . A dendrogram representing the phenotypic differences between strain $7-10-1-\mathrm{b}^{\mathrm{T}}$ and the Eggerthella type strains was constructed (Supplementary Fig. S1, available in IJSEM Online). Three distinct branches were observed and differentiate strain $7-10-1-\mathrm{b}^{\mathrm{T}}$ from the members of the genus Eggerthella. E. lenta and E. sinensis grouped together.

\section{Flavonoid activity}

Flavonoids are polyphenolic compounds that are widely found in fruits, vegetables, nuts, seeds, flowers, tea, wine and honey, and which are ingested in significant quantities as part of the normal diet in humans (Cushnie \& Lamb, 2005). Certain intestinal bacteria have a major role in the metabolism of flavonoids, which exhibit an array of health benefits to the host (Chun et al., 2007).

Flavonoid conversion/degradation was tested (for strain 7$10-1-\mathrm{b}^{\mathrm{T}}$ only) using the fluorescence-quenching assay as 
Table 1. Biochemical profiles of strain $7-10-1-b^{\top},[E$.$] hongkongensis DSM 16106^{\top}$, E. lenta DSM $2243^{\top}$ and E. sinensis DSM $16107^{\top}$

Strains: 1, strain 7-10-1-b $\mathrm{b}^{\mathrm{T}} ; 2$, [E.] hongkongensis DSM $16106^{\mathrm{T}} ; 3$, E. lenta DSM 2243 $3^{\mathrm{T}} ; 4$, E. sinensis DSM $16107^{\mathrm{T}}$. Cells of all strains are coccobacilli with a Gram-positive cell-wall architecture and staining reaction. All strains are positive for arginine dihydrolase and negative for alkaline phosphatase activity (data for E. lenta from Lau et al., 2004b). +, Positive; -, negative; v, variable. Data are from the present study unless indicated.

\begin{tabular}{|c|c|c|c|c|}
\hline Characteristic & 1 & 2 & 3 & 4 \\
\hline Catalase & + & + & $\mathrm{v}^{a_{\star}}$ & + \\
\hline \multicolumn{5}{|l|}{ Metabolism of: } \\
\hline$\beta$-Cyclodextrin & - & - & - & + \\
\hline Dextrin & + & - & - & - \\
\hline L-Fucose & - & - & - & + \\
\hline D-Glucose 6-phosphate & + & - & - & - \\
\hline D-Mannose & - & - & + & - \\
\hline 3-Methyl D-glucose & - & + & - & - \\
\hline Palatinose & - & + & - & - \\
\hline Raffinose & - & - & + & - \\
\hline L-Rhamnose & - & + & - & - \\
\hline Trehalose & - & - & + & - \\
\hline Acetic acid & - & - & - & + \\
\hline$\alpha$-Ketobutyric acid & - & - & - & + \\
\hline$\alpha$-Ketovaleric acid & - & - & - & + \\
\hline Pyruvic acid & + & - & - & - \\
\hline Pyruvic acid methyl ester & + & - & - & - \\
\hline Urocanic acid & - & + & - & + \\
\hline L-Alanyl L-histidine & - & - & $\mathrm{V}$ & - \\
\hline L-Methionine & + & + & - & - \\
\hline L-Phenylalanine & + & - & - & + \\
\hline L-Threonine & - & + & $\mathrm{V}$ & - \\
\hline L-Valine & + & + & - & - \\
\hline L-Valine plus L-aspartic acid & + & + & - & - \\
\hline $2^{\prime}$-Deoxyadenosine & - & - & - & + \\
\hline Uridine $5^{\prime}$-monophosphate & - & + & - & - \\
\hline Reduction of nitrate & - & - & $\mathrm{v}^{a}$ & - \\
\hline \multicolumn{5}{|l|}{ Activity of : } \\
\hline$\alpha$-Fucosidase & - & - & $\mathrm{v}^{a}$ & - \\
\hline$\beta$-Glucosidase & - & $-\dagger$ & $-{ }^{a}$ & - \\
\hline Alanine arylamidase & - & - & $\mathrm{v}^{a}$ & - \\
\hline Arginine arylamidase & - & - & $\mathrm{v}^{a}$ & + \\
\hline Glycine arylamidase & - & - & $\mathrm{v}^{a}$ & - \\
\hline Histidine arylamidase & - & - & $\mathrm{v}^{a}$ & - \\
\hline Leucine arylamidase & - & - & $\mathrm{v}^{a}$ & - \\
\hline Phenylalanine arylamidase & - & - & $\mathrm{v}^{a}$ & - \\
\hline Proline arylamidase & - & - & $\mathrm{v}^{a}$ & - \\
\hline Serine arylamidase & - & - & $\mathrm{v}^{a}$ & - \\
\hline Tyrosine arylamidase & - & - & $v^{b}$ & - \\
\hline DNA G $+\mathrm{C}$ content $(\mathrm{mol} \%)$ & 66.4 & $61.1^{c}, 61.8$ & $62.0,63.8^{c}$ & $64.9^{c}, 65.6$ \\
\hline
\end{tabular}

${ }^{*}$ Data from: $a$, Lau et al. (2004b), b, Kageyama et al. (1999b); c, Maruo et al. (2008). These studies also included data from other strains. $\dagger$ Different from result reported by Lau et al. (2004b).

described by Schoefer et al. (2001) although using Schaedler anaerobic agar (Oxoid) as the basal medium. In brief, nylon membranes were soaked with individual flavonoids [quercetin $(10 \mathrm{mM})$, rutin $(10 \mathrm{mM})$, genistein $(25 \mathrm{mM})$ or phloretin $(25 \mathrm{mM})]$ and a fluorescent dye, DPH (1, 6-diphenyl-1,3,5-hexatriene), and placed onto the 
surface of the basal medium. Strain $7-10-1-b^{T}$ was subsequently inoculated onto the surface of the membranes and incubated under anaerobic conditions for $48-72 \mathrm{~h}$ at $37{ }^{\circ} \mathrm{C}$. Plates were subsequently checked for fluorescence using a UV lamp. No significant conversion/degradation of quercetin, rutin, genistein or phloretin was observed for strain $7-10-1-b^{\mathrm{T}}$.

\section{Molecular phylogenetic analysis}

For $16 \mathrm{~S}$ rRNA gene sequence determination and phylogenetic analysis, one colony was picked from a plate culture for DNA preparation, suspended in $60 \mu \mathrm{l}$ TE buffer $(10 \mathrm{mM}$ Tris/ $\mathrm{HCl}, 1 \mathrm{mM}$ EDTA, $\mathrm{pH}$ 8.0) and boiled at $95{ }^{\circ} \mathrm{C}$ for $5 \mathrm{~min}$ and the lysate was centrifuged briefly. A $1 \mu \mathrm{l}$ aliquot of the supernatant was used for PCR (Mullis \& Faloona, 1987) targeting the 16S rRNA gene with primers $27 \mathrm{~F}\left(5^{\prime}\right.$ AGAGTTTGATCMTGGCTCAG-3') and 1492R (5'TACGGYTACCTTGTTACGACTT-3') (Lane, 1991). Direct sequence determination of the PCR-amplified DNA was carried out using an ABI3130xl DNA sequencer and Taq cycle-sequencing reactions according to the manufacturer's instructions (Applied Biosystems). Sequences were compared initially with the EMBL nucleotide sequence database (Kanz et al., 2005) using the BLAST tool (Altschul et al., 1990) and were subsequently aligned with related taxa using CLUSTAL W (Thompson et al., 1994). Phylogenetic relationships were estimated for evolutionarily conserved regions in MEGA (Tamura et al., 2007) using the Jukes-Cantor correction model (Jukes \& Cantor, 1969). A dendrogram representing evolutionary distances was generated by minimum evolution (Rzhetsky \& Nei, 1992) with support for internal branches estimated from 500 bootstrap resamplings (Felsenstein, 1985). Tree topology was confirmed by maximum-likelihood using the online tool PHYML (Guindon \& Gascuel, 2003; Guindon et al., 2005) and was also calculated using the Jukes-Cantor model of substitution and with 500 bootstrap resamplings (Supplementary Fig. S2).

A nearly complete $16 \mathrm{~S}$ rRNA gene sequence (1431 bp) was obtained for isolate 7-10-1- $\mathrm{b}^{\mathrm{T}}$ which, following preliminary screening against 16S rRNA gene sequences from EMBL (Kanz et al., 2005), indicated that the strain belonged to the family Coriobacteriaceae. The sequence was aligned with all currently accepted members of the Coriobacteriaceae and a phylogenetic tree representing minimum-evolutionary distances was constructed (Jukes-Cantor) with MEGA (Tamura et al., 2007) (Fig. 2). On the basis of 16S rRNA gene sequence similarity, strain $7-10-1-b^{T}$ grouped with members of the genus Eggerthella as part of a larger assemblage that also included Denitrobacterium detoxificans $\mathrm{NPOH}_{1}{ }^{\mathrm{T}}$, Adlercreutzia equolifaciens $\mathrm{FJC}-\mathrm{B} 9^{\mathrm{T}}$ and Asaccharobacter celatus do $03^{\mathrm{T}}$. Our results indicate that the latter two taxa probably represent members of the same genus. However, whether they represent the same or different species requires further evaluation. The observed groupings were confirmed using maximum-likelihood (Supplementary Fig. S2).

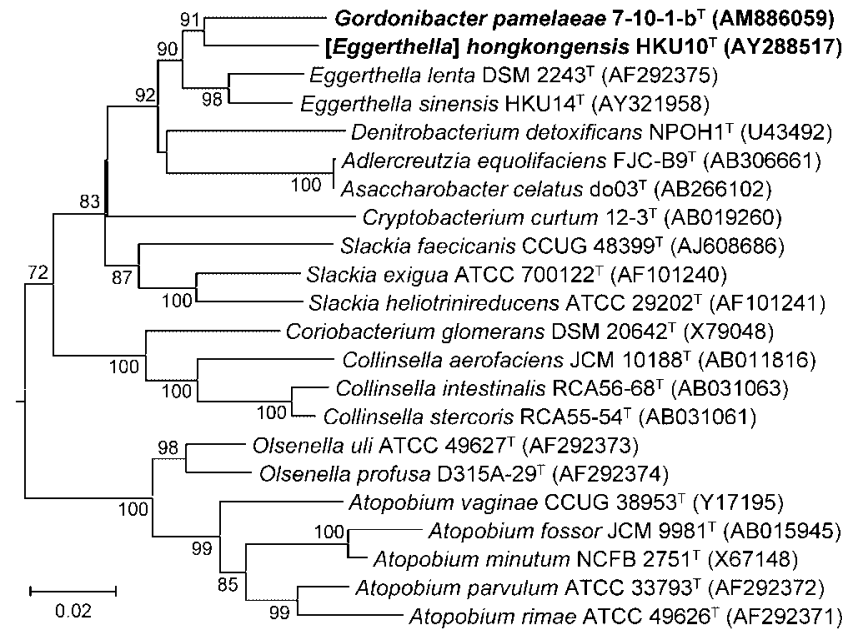

Fig. 2. Phylogenetic tree derived from minimum evolutionary distances (Jukes-Cantor) between 16S rRNA gene sequences of strain $7-10-1-b^{\top}$, the type strains of [E.] hongkongensis, $E$. sinensis and $E$. lenta and other representatives of the family Coriobacteriaceae. GenBank accession numbers are presented in parentheses. Bar, $2 \%$ nucleotide sequence difference. Numbers at nodes $(\geqslant 70 \%)$ indicate support for internal branches within the tree obtained by bootstrap analysis (percentages of 500 resamplings).

The closest relatives of strain $7-10-1-\mathrm{b}^{\mathrm{T}}$ are [E.] hongkongensis $\mathrm{HKU}_{10}^{\mathrm{T}}$ (94.6\% 16S rRNA gene sequence similarity), E. lenta DSM $2243^{\mathrm{T}}(93.1 \%)$ and E. sinensis HKU $14^{\mathrm{T}}$ $(95.2 \%)$. Strain $7-10-1-\mathrm{b}^{\mathrm{T}}$ formed a distinct lineage independent of the Eggerthella species which, also confirmed with maximum-likelihood (Supplementary Fig. S2), is evidenced by a stable branching point with high bootstrap values of 87,91 and $94 \%$ (percentages of 500 resamplings), respectively.

Also of interest was the relatively low 16S rRNA gene sequence similarity of $\left[E\right.$.] hongkongensis $\mathrm{HKU}_{10}{ }^{\mathrm{T}}$ to $E$. sinensis HKU14 ${ }^{\mathrm{T}}$ (95\%) and E. lenta DSM $2243^{\mathrm{T}}(93.5 \%)$. This was reflected in the separation of these taxa into two distinct groups and is suggestive of the fact that the genus Eggerthella is in need of revision. On the basis of these $16 \mathrm{~S}$ rRNA gene sequence similarity values, DNA-DNA hybridization work was not undertaken, since the work of Nakazawa \& Hoshino (2004) has shown that such low values correlate with low DNA-DNA hybridization values. Nevertheless, in consideration of the revised minimum sequence identity $(94.9 \pm 0.4 \%)$ required to describe a new genus (Yarza et al., 2008), it is likely that both strain 7-10$1-\mathrm{b}^{\mathrm{T}}$ and $[E$.$] hongkongensis represent new genera.$

\section{$G+C$ content of DNA}

Isolation of DNA for determination of the DNA $G+C$ content by HPLC followed described procedures (Cashion et al., 1977; Mesbah et al., 1989). The G +C content of the 
DNA of strain $7-10-1-b^{\mathrm{T}}$ was $66.4 \mathrm{~mol} \%$. This high $\mathrm{G}+\mathrm{C}$ content is generally observed for the class Actinobacteria and is marginally higher than that observed for E. lenta, $E$. sinensis or [E.] hongkongensis (Table 1).

\section{Chemotaxonomy}

Fatty acids were analysed as methyl ester derivatives prepared from $10 \mathrm{mg}$ dry cell material. Cells were subjected to differential hydrolysis in order to detect ester-linked and non-ester-linked (amide-bound) fatty acids (Labrenz et al., 1998). Fatty acid methyl esters were analysed by gas chromatography using a $0.2 \mu \mathrm{m} \times 25 \mathrm{~m}$ non-polar capillary column and flame-ionization detection. The run conditions were: injection and detector port temperature $300{ }^{\circ} \mathrm{C}$, inlet pressure $60 \mathrm{kPa}$, split ratio $50: 1$, injection volume $1 \mu \mathrm{l}$, with a temperature program from 130 to $310{ }^{\circ} \mathrm{C}$ at a rate of $4{ }^{\circ} \mathrm{C} \mathrm{min}^{-1}$.

Differences in fatty acid components detected by GC analysis $(\geqslant 0.5 \%)$ were compared using the Bray-Curtis similarity algorithm (Primer 6, version 6.1.6; Primer-E). A dendrogram representing the percentage similarity in fatty acid composition between strain $7-10-1-b^{T}$ and the Eggerthella type strains was constructed using group average hierarchical clustering (Primer 6). The major fatty acid components that contributed to differences in fatty acid composition were assessed using the Similarity Percentages (SIMPER) tool in Primer 6. A table listing these components $(\geqslant 5 \%)$ and their percentage composition in each of the strains was generated (Supplementary Table S1). Complete fatty acid compositions of all analysed strains are presented in Table 2.

An overall greater percentage of saturated $(89 \%)$ rather than monounsaturated ( $8 \%$ ) fatty acids was extracted from cells of strain 7-10-1-b ${ }^{\mathrm{T}}$. In comparison, cells of E. sinensis DSM $16107^{\mathrm{T}}$ and E. lenta DSM $2243^{\mathrm{T}}$ contained smaller amounts of saturated fatty acids (63 and $61 \%$, respectively) and larger quantities of monounsaturated components (33 and $36 \%$, respectively). Almost equal proportions of saturated and monounsaturated fatty acids were observed for [E.] hongkongensis DSM $16106^{\mathrm{T}}$ (45 and 51\%, respectively), which was also the only strain to contain polyunsaturated fatty acids (namely $18: 2 \omega 6,9 c$ ).

Of particular interest was the relatively large percentage of branched-chain (saturated) fatty acids extracted from cells of strain $7-10-1-\mathrm{b}^{\mathrm{T}}(41 \%)$ and their almost complete absence from [E.] hongkongensis DSM $16106^{\mathrm{T}}(0.6 \%)$ compared with E. sinensis DSM $16107^{\mathrm{T}}(22 \%)$ and E. lenta DSM $2243^{\mathrm{T}}$ (13\%). Analysis of the major components that contributed to these differences revealed strain $7-10-1-b^{\mathrm{T}}$ to contain larger amounts of the branched, saturated fatty acid 15:0 anteiso (the predominant component extracted) than obtained for $[E$.] hongkongensis DSM $16106^{\mathrm{T}}$, E. lenta DSM $2243^{\mathrm{T}}$ or E. sinensis DSM $16107^{\mathrm{T}}$ (Supplementary Table S1). In contrast, larger amounts of the unbranched saturated 16:0 dimethylacetal
Table 2. Fatty acid compositions of strain $7-10-1-b^{\top}$ and type strains of $[E$.$] hongkongensis, E$. lenta and $E$. sinensis

Strains: 1, strain 7-10-1-b ${ }^{\mathrm{T}} ; 2$, [E.] hongkongensis DSM $16106^{\mathrm{T}} ; 3$, E. lenta DSM $2243^{\mathrm{T}} ; 4$, E. sinensis DSM $16107^{\mathrm{T}}$. Values are percentages of the total mean amount derived from duplicate cellular fatty acid extractions. Total percentages of saturated (iso- and anteiso-branched and unbranched forms) and monounsaturated fatty acids are given in bold. Unknown fatty acids are identified by their equivalent chain length.

\begin{tabular}{|c|c|c|c|c|}
\hline Fatty acid & 1 & 2 & 3 & 4 \\
\hline \multicolumn{5}{|l|}{ Saturated } \\
\hline \multicolumn{5}{|l|}{ Iso-branched } \\
\hline $13: 0$ iso & 1.09 & 0 & 0 & 0 \\
\hline $13: 0$ iso $3-\mathrm{OH}$ & 1.50 & 0 & 0 & 0 \\
\hline $14: 0$ iso & 6.78 & 0 & 3.91 & 9.25 \\
\hline $15: 0$ iso DMA & 6.07 & 0 & 0 & 0 \\
\hline $15: 0$ iso & 2.96 & 0 & 0.55 & 0 \\
\hline $16: 0$ iso & 0.66 & 0 & 0 & 0.65 \\
\hline Total iso-branched & 19.06 & $\mathbf{0}$ & 4.46 & 9.90 \\
\hline \multicolumn{5}{|l|}{ Anteiso-branched } \\
\hline $13: 0$ anteiso & 0 & 0 & 0 & 0.52 \\
\hline $15: 0$ anteiso & 19.79 & 0.63 & 8.50 & 11.43 \\
\hline $17: 0$ anteiso DMA & 1.76 & 0 & 0 & 0 \\
\hline Total anteiso-branched & 21.55 & 0.63 & 8.50 & 11.95 \\
\hline (Total branched) & $(40.61)$ & $(0.63)$ & $(12.96)$ & $(21.85)$ \\
\hline \multicolumn{5}{|l|}{ Unbranched } \\
\hline $12: 0$ & 2.70 & 4.26 & 1.49 & 0.58 \\
\hline $14: 0$ & 8.71 & 3.78 & 6.51 & 4.15 \\
\hline $14: 0 \mathrm{DMA}$ & 9.72 & 0.63 & 1.96 & 2.71 \\
\hline $16: 0$ & 2.42 & 3.92 & 3.50 & 4.12 \\
\hline $16: 0$ DMA & 13.47 & 23.08 & 29.42 & 22.53 \\
\hline 16:0 aldehyde & 0 & 0 & 0.51 & 0 \\
\hline Unknown 16.107 & 4.05 & 0 & 0.59 & 1.53 \\
\hline $17: 0$ & 0.68 & 0 & 0 & 0 \\
\hline $18: 0$ & 0.78 & 2.59 & 0.71 & 0.83 \\
\hline $18: 0 \mathrm{DMA}$ & 1.52 & 5.93 & 3.12 & 4.40 \\
\hline Summed feature $5^{\star}$ & 0.52 & 0 & 0 & 0 \\
\hline Summed feature $13^{\star}$ & 4.20 & 0 & 0 & 0 \\
\hline (Total unbranched) & $(48.77)$ & $(44.19)$ & $(47.81)$ & $(40.85)$ \\
\hline Total saturated & 89.38 & 44.82 & 60.77 & 62.70 \\
\hline \multicolumn{5}{|l|}{ Monounsaturated } \\
\hline $14: 1 \omega 5 c$ & 0 & 1.64 & 1.26 & 0.84 \\
\hline $16: 1 \omega 7 c$ & 1.69 & 4.83 & 2.27 & 1.42 \\
\hline $16: 1 \omega 7 c$ DMA & 0.90 & 1.04 & 1.56 & 1.47 \\
\hline $18: 1 \omega 7 c$ DMA & 0 & 3.77 & 1.71 & 1.48 \\
\hline $18: 1 \omega 9 c$ DMA & 1.47 & 6.75 & 5.99 & 7.04 \\
\hline $18: 1 \omega 9 c$ & 3.65 & 30.37 & 22.02 & 19.74 \\
\hline Summed feature $10^{*}$ & 0 & 2.36 & 1.36 & 1.26 \\
\hline Total monounsaturated & 7.71 & 50.76 & 36.17 & 33.25 \\
\hline \multicolumn{5}{|l|}{ Polyunsaturated } \\
\hline $18: 2 \omega 6,9 c$ & 0 & 0.78 & 0 & 0 \\
\hline
\end{tabular}

${ }^{\star}$ Summed features contain the following fatty acids: summed feature 5, 15:0 DMA and/or 14:0 3-OH; summed feature 10, 18:167c and/ or unknown 17.834; summed feature 13, 15:0 anteiso DMA and/or 14:0 2-OH. 
(DMA) and the monounsaturated fatty acid $18: 1 \omega 9 c$ were observed for [E.] hongkongensis DSM $16106^{\mathrm{T}}$, E. lenta DSM $2243^{\mathrm{T}}$ and E. sinensis DSM $16107^{\mathrm{T}}$, consistent with results reported by Maruo et al. (2008). These differences were reflected in the hierarchical clustering of the strains and revealed the presence of at least three distinct branches representing three independent taxa (Fig. 3). A notable observation was the low similarity of strain $7-10-1-b^{\mathrm{T}}$ to all other type strains $(47 \%)$ and the separation of $[E$.] hongkongensis DSM $16106^{\mathrm{T}}$ from E. sinensis DSM $16107^{\mathrm{T}}$ and E. lenta DSM $2243^{\mathrm{T}}$ (74\% similarity), which clustered together ( $85 \%$ similarity). This is consistent with the findings of the phenotypic and 16S rRNA gene sequence analyses of these strains.

\section{Polar lipids and quinones}

Respiratory lipoquinones and polar lipids were extracted from $100 \mathrm{mg}$ freeze-dried cell material using the two-stage method described by Tindall (1990a, b). Respiratory quinones were extracted using methanol/hexane (Tindall, $1990 \mathrm{a}, \mathrm{b})$ and the polar lipids were extracted by adjusting the remaining methanol/ $0.3 \%$ aqueous $\mathrm{NaCl}$ phase (containing the cell debris) to give a chloroform/methanol/ $0.3 \%$ aqueous $\mathrm{NaCl}$ mixture $(1: 2: 0.8$, by vol.). The extraction solvent was stirred overnight and the cell debris was then pelleted by centrifugation. Polar lipids were recovered into the chloroform phase by adjusting the chloroform/methanol/ $0.3 \%$ aqueous $\mathrm{NaCl}$ mixture to a ratio of $1: 1: 0.9$ (by vol.).

Respiratory lipoquinones were separated into their different classes (menaquinones and ubiquinones) by TLC on silica gel (Macherey-Nagel art. no. 805 023), using hexane/ tert-butylmethylether $(9: 1 \mathrm{v} / \mathrm{v})$ as solvent. UV-absorbing bands corresponding to menaquinones or ubiquinones were removed from the plate and further analysed by HPLC. This step was carried out on an LDC Analytical HPLC (Thermo Separation Products) fitted with a reversed-phase column (Macherey-Nagel; $2 \times 125 \mathrm{~mm}$, $\left.3 \mu \mathrm{m}, \mathrm{RP}_{18}\right)$ using methanol/heptane $(9: 1 \mathrm{v} / \mathrm{v})$ as the

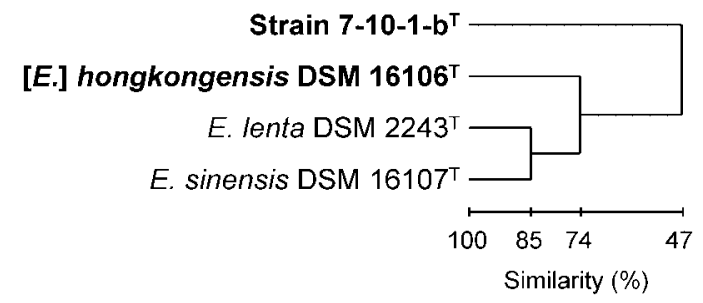

Fig. 3. Dendrogram representing the percentage similarity in cellular fatty acids between strain $7-10-1-b^{\top}$ and the type strains of $[E$.] hongkongensis, $E$. lenta and $E$. sinensis. Values represent means of duplicate fatty acid extractions and, using group average hierarchical clustering (Bray-Curtis similarity algorithm; Primer 6), are presented as group averages. eluent. Respiratory lipoquinones were detected by absorbance at $269 \mathrm{~nm}$.

Polar lipids were separated by two-dimensional silica gel TLC (Macherey-Nagel art. no. 818 135). The first direction was developed in chloroform/methanol/water $(65: 25: 4$, by vol.) and the second in chloroform/methanol/acetic acid/water ( $80: 12: 15: 4$, by vol.). Total lipid material and specific functional groups were detected using dodecamolybdophosphoric acid (total lipids), Zinzadze reagent (phosphate), ninhydrin (free amino groups), periodate-Schiff ( $\alpha$-glycols), Dragendorff reagent (quaternary nitrogen), anisaldehydesulphuric acid and $\alpha$-naphthol (glycolipids).

The presence of DMAs in the fatty acid patterns is consistent with the presence of plasmalogens (vinyl ethers) in the polar lipids. However, it should be noted that the interpretation of the data presented here and in other publications requires some caution. While our results only indicate that DMAs are present, Maruo et al. (2008), Verhulst et al. (1987) and Anderson et al. (2000) also report the presence of the equivalent chain-length aldehydes. In contrast, Itoh et al. (1995) report only the presence of aldehydes. These differences may be due to the slightly different methods used and it should be remembered that, under certain conditions, plasmalogens hydrolyse to give first the appropriate long-chain aldehyde, which may be modified to give the equivalent DMA. The presence of aldehydes and absence of DMAs would suggest that the methods used have not converted the aldehydes to the corresponding DMA, whereas the presence of both (aldehydes and DMAs) would suggest that the conversion of the aldehydes to DMAs is not complete, while the presence of only DMAs would suggest that the reaction has gone to completion. This would need to be investigated further, but is significant in the evaluation of the data. Irrespective of which method is used, a particular aldehyde and its equivalent DMA should be treated as being derived from the same parent plasmalogen. In some cases, neither aldehydes nor DMAs are reported in members of the family Coriobacteriaceae, although it is not clear whether they were present, but simply not recorded in the results (Minamida et al., 2008; Lawson et al., 2005).

The two predominant menaquinones detected in all strains were menaquinone 6 (MK-6) and monomethylmenaquinone 6 (MMK-6) (Supplementary Table S2). Dimethylmenaquinones, in particular dimethylmenaquinone 6 (DMMK-6), were not detected in any of the strains, but this may have been due to the failure to detect this compound by HPLC, since only relatively small amounts of menaquinones were observed by TLC. DMMK- 6 has been reported in a number of taxa, including members of genus Eggerthella (Collins et al., 1985; Fernandez \& Collins, 1987; Maruo et al., 2008), although the relative amounts vary, suggesting both growth conditions-related variations as well as taxon-specific differences. The unidentified quinone reported in Asaccharobacter celatus (Minamida et al., 2008) may also be DMMK-6. MK-6 was the major respiratory 
lipoquinone in strain 7-10-1-b ${ }^{\mathrm{T}}$ (59.5\%; with 40.5\% MMK6), [E.] hongkongensis DSM $16106^{\mathrm{T}}$ (67.8\%; with $32.2 \%$ MMK-6) and E. lenta DSM $2243^{\mathrm{T}}$ (63.7\%), whereas MMK-6 was predominant in E. sinensis DSM $16107^{\mathrm{T}}(60.4 \%)$ (Supplementary Table S2). These results also suggest that routine determination of the menaquinone composition within the family Coriobacteriaceae should not be neglected.

To our knowledge, the polar lipid composition of members of the genus Eggerthella, or even other taxa within the family Coriobacteriaceae, has not been reported previously. In all strains examined, two major phospholipids were detected, phosphatidylglycerol and diphosphatidylglycerol, as well as up to four glycolipids. All four glycolipids ran with similar, but not identical, $R_{\mathrm{f}}$ values, suggesting structural differences that may be the result of differences in the sugars present and/or the configuration of their linkages, rather than the number of sugars present. This pattern of glycolipids appears to be unique within this group of organisms. This is particularly evident given the relatively conserved polar lipid profiles of strain $7-10-1-\mathrm{b}^{\mathrm{T}}$, E. lenta DSM $2243^{\mathrm{T}}$ and $E$. sinensis DSM $16107^{\mathrm{T}}$, which were characterized by the presence of two phospholipids, phosphatidylglycerol and diphosphatidylglycerol, and four glycolipids, GL1-GL4 (Supplementary Fig. S3). [E.] hongkongensis DSM $16106^{\mathrm{T}}$ displayed a similar pattern but lacked glycolipid GL3, further supporting its separation from the genus Eggerthella.

It is evident from the results presented here, which record for the first time the polar lipid, fatty acid (including plasmalogen-derived aldehydes and DMAs) and respiratory lipoquinone composition, that these three datasets are of value in the differentiation of organisms within the family Coriobacteriaceae. The presence of menaquinones and methylated menaquinones with six isoprenoid units is a feature that these organisms also share with certain members of the Epsilonproteobacteria (Carlone \& Anet, 1983; Moss et al., 1984; Collins et al., 1984; Collins \& Widdel, 1986), but they may be easily distinguished based on their fatty acid patterns. The presence of dimethylmenaquinones is, however, unique to this group of organisms. Clearly, such data may be of value in delineating higher taxa within this taxon. To date, the subclass Coriobacteridae, the order Coriobacteriales and the family Coriobacteriaceae are defined only in terms of $16 \mathrm{~S}$ rRNA gene signature nucleotides (Stackebrandt et al., 1997). The definition of these taxa is such that the signatures that define the subclass also define the order and family. It would seem appropriate to examine the value of chemotaxonomy in improving the definition of the order and family, or even re-examining the taxonomic infrastructure within the subclass. It is worthwhile noting that the papers of Dewhirst et al. (2001), Rodriguez Jovita et al. (1999), Collins \& Wallbanks (1992), Lau et al. (2004b), Nakazawa et al. (1999), Wade et al. (1999), Kageyama \& Benno (2000) and Kageyama et al. (1999a, b, c) do not include any fatty acid, polar lipid or quinone data. Such work may also have consequences for the definition of taxon-specific gene probes (Harmsen et al., 2000).
In the present study, we investigated the phylogenetic, physiological/biochemical and chemotaxonomic properties of strain $7-10-1-b^{\mathrm{T}}$ (an isolate from the colon of a patient with active Crohn's disease) in comparison with all type strains of the genus Eggerthella. Based on the strain's unique $16 \mathrm{~S}$ rRNA gene sequence, its phenotypic and chemotaxonomic properties and the data obtained for its nearest neighbours, two new genera, one novel species and an emended description of the genus Eggerthella are proposed within the family Coriobacteriaceae. Thus, we propose that strain $7-10-1-\mathrm{b}^{\mathrm{T}}$ should be assigned as the type strain of a novel species within a new genus, for which we propose the name Gordonibacter pamelaeae gen. nov., sp. nov., and that [Eggerthella] hongkongensis Lau et al. 2006 should be transferred to a novel genus, Paraeggerthella gen. nov., as Paraeggerthella hongkongensis gen. nov., comb. nov. The characteristics that discriminate the newly proposed taxa are presented in Tables 1 and 2 .

The prevalence of strain $7-10-1-\mathrm{b}^{\mathrm{T}}$ amongst individuals with Crohn's disease and its association with the mucosa as an opportunistic pathogen or a member of the normal flora requires further investigation.

\section{Description of Gordonibacter gen. nov.}

Gordonibacter (Gor.do'ni.bac'ter. N.L. masc. n. Gordon named after Jeffrey I. Gordon, MD, the Dr Robert J. Glaser Distinguished University Professor and Director of the Center for Genome Sciences at Washington University School of Medicine, St. Louis, MO, USA; N.L. masc. n. bacter a rod; N.L. masc. n. Gordonibacter a rod named after Jeffrey I. Gordon).

Gram-positive, motile, non-spore-forming coccobacilli (0.5$0.6 \times 0.8-1.2 \mu \mathrm{m})$. Obligately anaerobic. Cellular fatty acids consist mainly $(\sim 90 \%)$ of saturated fatty acids (predominantly $\mathrm{C}_{14}$ and $\mathrm{C}_{15}$ ) and include $12: 0,13: 0$ iso, 13:0 iso 3$\mathrm{OH}, 14: 0,14: 0$ iso, 14:0 DMA, 15:0 iso DMA, 15:0 iso, $15: 0$ anteiso, $16: 0,16: 0$ iso, $16: 0$ DMA, $16: 1 \omega 7 c, 16: 1 \omega 7 c$ DMA, unknown ECL 16.107, 17:0, 17:0 anteiso DMA, $18: 0,18: 0$ DMA, $18: 1 \omega 9 c$ DMA and $18: 1 \omega 9 c$, the major component is $15: 0$ anteiso. The major respiratory lipoquinone present is menaquinone MK-6; MMK-6 is a minor component. Major polar lipids are phosphatidylglycerol, diphosphatidylglycerol and four glycolipids (GL1-GL4). Oxidation/fermentation of arabinose, glucose, mannose, raffinose, trehalose and xylose is not observed. Nitrate is not reduced. The $\mathrm{G}+\mathrm{C}$ content of the genomic DNA of the single known strain is $66.4 \mathrm{~mol} \%$. The type and only species of the genus is Gordonibacter pamelaeae.

\section{Description of Gordonibacter pamelaeae sp. nov.}

Gordonibacter pamelaeae [pa.me'la.eae. N.L. fem. n. pamelaeae named after Dr Pamela Lee Oxley (née Fredericks), biochemist, environmentalist, teacher, mentor and mother]. 
Morphology and general characteristics are as described for the genus, with cells displaying a conical cell apex. Growth is generally slow on BHI and Schaedler anaerobic media (Oxoid) supplemented with $5 \%$ defibrinated horse blood, with pale-white, semi-translucent colonies forming after $48-72 \mathrm{~h}$ of incubation at $37^{\circ} \mathrm{C}$ in an anaerobic environment. Growth is enhanced by the supplementation of the basal medium with $1 \%$ arginine hydrochloride $(\mathrm{w} / \mathrm{v})$. Subpolarly inserted flagella are apparent when cells are grown in BHI medium. Cells are catalase-positive and show hydrolysis of arginine. The carbon sources Lmethionine, L-phenylalanine, L-valine, L-valine plus Laspartic acid, dextrin and D-glucose 6-phosphate are metabolized. Only weak conversion of pyruvic acid and pyruvic acid methyl ester is observed. All other organic substrates included in the Biolog AN MicroPlate are not metabolized. Chemotaxonomy is as given for the genus.

The type strain is $7-10-1-\mathrm{b}^{\mathrm{T}}\left(=\mathrm{DSM} 19378^{\mathrm{T}}=\mathrm{CCUG}\right.$ $55131^{\mathrm{T}}$ ), isolated from the sigmoid region of the colon of a patient suffering from active Crohn's disease.

\section{Description of Paraeggerthella gen. nov.}

Paraeggerthella ( $\mathrm{Pa}^{\prime}$ ra.eg.ger.thel'la. L. prep. para beside; N.L. fem. n. Eggerthella a bacterial genus name; N.L. fem. n. Paraeggerthella beside Eggerthella, named in recognition of the close relationship to the genus Eggerthella).

Characteristics of the genus are as described previously for [Eggerthella] hongkongensis (Lau et al., 2004b; Maruo et al., 2008). In addition, cellular fatty acids consist of saturated and monounsaturated fatty acids (45:51 in the type strain of the type species) (predominantly $\mathrm{C}_{16}$ and $\mathrm{C}_{18}$ ) and include $12: 0,14: 0,14: 0$ DMA, $14: 1 \omega 5 c, 15: 0$ anteiso, $16: 0,16: 0$

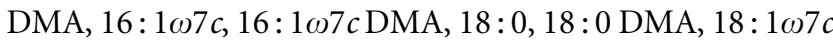

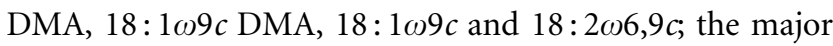
component is $18: 1 \omega 9 c$. The major respiratory lipoquinone present is menaquinone MK-6; MMK-6 is a minor component. Polar lipids consist of phosphatidylglycerol, diphosphatidylglycerol and three glycolipids (GL1, GL2 and GL4). Oxidation/fermentation of arabinose, glucose, mannose, raffinose, trehalose and xylose is not observed. The $\mathrm{G}+\mathrm{C}$ content of the genomic DNA of the only known strain is $61.1-61.8 \mathrm{~mol} \%$. The type and only species of the genus is Paraeggerthella hongkongensis.

\section{Description of Paraeggerthella hongkongensis (Lau et al. 2006) comb. nov.}

Basonym: Eggerthella hongkongensis Lau et al. 2006.

Characteristics of the species are as described previously by Lau et al. (2004b) and Maruo et al. (2008). In additional, physiological testing using the two API kits Rapid ID32A and API 20A reveals just one positive reaction, for arginine dihydrolase. Results obtained with Biolog AN MicroPlates indicate that the following substrates are metabolized: 3methyl D-glucose, palatinose, urocanic acid, L-methionine,
L-threonine, L-valine, L-valine plus L-aspartic acid and uridine $5^{\prime}$-monophosphate. Additionally, weak conversion of rhamnose is observed. The other organic substrates included in the Biolog AN MicroPlate are not metabolized. Chemotaxonomy is as given for the genus.

The type strain is $\mathrm{HKU}_{10}^{\mathrm{T}}$ (=DSM $16106^{\mathrm{T}}=\mathrm{CCUG}$ $49250^{\mathrm{T}}$ ).

\section{Emended description of the genus Eggerthella Wade et al. 1999}

When Wade et al. (1999) transferred Eubacterium lentum to the genus Eggerthella, the authors referred to the description of Eubacterium lentum published by Moore et al. (1971). However, the Approved Lists of Bacterial Names (Skerman et al., 1980, 1989) refer to Holdeman et al. (1977) as the source of the description for Eubacterium lentum. In emending the description of the genus Eggerthella Wade et al. 1999, Maruo et al. (2008) also make reference to the publication of Moore et al. (1971) and not to Holdeman et al. (1977). It is important to remember that, when a name was included on the Approved Lists of Bacterial Names (Skerman et al., 1980, 1989), the type of the name and the description which accompanies the name are those referenced on the Approved Lists of Bacterial Names.

The description is as given previously (Moore et al., 1971; Holdeman et al., 1977; Kageyama et al., 1999b; Wade et al., 1999; Maruo et al., 2008) with the following modifications. Respiratory lipoquinones consist of MK-6 and MMK-6; MK-6 is the major component in E. lenta and MMK-6 in E. sinensis. Polar lipids consist of two phospholipids, phosphatidylglycerol and diphosphatidylglycerol, and four glycolipids, GL1-GL4. The G + C content of the genomic DNA of the known species is $62.0-63.8 \mathrm{~mol} \%$ (E. lenta) and $64.9-65.6 \mathrm{~mol} \%$ (E. sinensis). The genus comprises two known species, Eggerthella lenta (the type species) and E. sinensis.

\section{Acknowledgements}

We gratefully acknowledge Dr Peter Schumann for conducting the $\mathrm{G}+\mathrm{C}$ analyses. We also thank Macarena Marin, Eva Medina and Ed Moore for their valuable intellectual input. This work was supported by a National Genome Research Network (NGFN II) grant (NIE-S06T14).

\section{References}

Altschul, S. F., Gish, W., Miller, W., Myers, E. W. \& Lipman, D. J. (1990). Basic local alignment search tool. J Mol Biol 215, 403-410.

Anderson, R. C., Rasmussen, M. A., Jensen, N. S. \& Allison, M. J. (2000). Denitrobacterium detoxificans gen. nov., sp. nov., a ruminal bacterium that respires on nitrocompounds. Int J Syst Evol Microbiol 50, 633-638.

Carlone, G. M. \& Anet, F. A. L. (1983). Detection of menaquinone- 6 and a novel methyl-substituted menaquinone-6 in Campylobacter jejuni and Campylobacter fetus subsp. fetus. J Gen Microbiol 129, 3385-3393. 
Cashion, P., Holder-Franklin, M. A., McCully, J. \& Franklin, M. (1977). A rapid method for the base ratio determination of bacterial DNA. Anal Biochem 81, 461-466.

Chan, R. C. \& Mercer, J. (2008). First Australian description of Eggerthella lenta bacteraemia identified by $16 \mathrm{~S}$ rRNA gene sequencing. Pathology 40, 409-410.

Chun, O. K., Chung, S. J. \& Song, W. O. (2007). Estimated dietary flavonoid intake and major food sources of U.S. adults. J Nutr 137, 1244-1252.

Collins, M. D. \& Wallbanks, S. (1992). Comparative sequence analyses of the 16S rRNA genes of Lactobacillus minutus, Lactobacillus rimae and Streptococcus parvulus: proposal for the creation of a new genus Atopobium. FEMS Microbiol Lett 95, 235-240.

Collins, M. D. \& Widdel, F. (1986). Respiratory quinone of sulfatereducing and sulfur-reducing bacteria: a systematic investigation. Syst Appl Microbiol 8, 8-18.

Collins, M. D., Costas, M. \& Owen, R. J. (1984). Isoprenoid quinone composition of representatives of the genus Campylobacter. Arch Microbiol 137, 168-170.

Collins, M. D., Fernandez, F. \& Howarth, O. W. (1985). Isolation and characterization of a novel vitamin-K from Eubacterium lentum. Biochem Biophys Res Commun 133, 322-328.

Cushnie, T. P. \& Lamb, A. J. (2005). Antimicrobial activity of flavonoids. Int J Antimicrob Agents 26, 343-356.

Dewhirst, F. E., Paster, B. J., Tzellas, N., Coleman, B., Downes, J., Spratt, D. A. \& Wade, W. G. (2001). Characterization of novel human oral isolates and cloned $16 \mathrm{~S}$ rDNA sequences that fall in the family Coriobacteriaceae: description of Olsenella gen. nov., reclassification of Lactobacillus uli as Olsenella uli comb. nov. and description of Olsenella profusa sp. nov. Int J Syst Evol Microbiol 51, 1797-1804.

Doetsch, R. N. (1981). Determinative methods of light microscopy. In Manual of Methods for General Bacteriology, pp. 21-33. Edited by P. Gerhardt, R. G. E. Murray, R. N. Costilow, E. W. Nester, W. A. Wood, N. R. Krieg \& G. H. Phillips. Washington, DC: American Society for Microbiology.

Dombek, P. E., Johnson, L. K., Zimmerley, S. T. \& Sadowsky, M. J. (2000). Use of repetitive DNA sequences and the PCR to differentiate Escherichia coli isolates from human and animal sources. Appl Environ Microbiol 66, 2572-2577.

Eggerth, A. H. (1935). The gram-positive non-spore-bearing anaerobic bacilli of human faeces. J Bacteriol 30, 277-299.

Felsenstein, J. (1985). Confidence limits on phylogenies: an approach using the bootstrap. Evolution 39, 783-791.

Felsenstein, J. (1989). PHYLIP - phylogeny inference package (version 3.2). Cladistics 5, 164-166.

Fernandez, F. \& Collins, M. D. (1987). Vitamin K composition of anaerobic gut bacteria. FEMS Microbiol Lett 41, 175-180.

Golyshina, O. V., Pivovarova, T. A., Karavaiko, G. I., Kondrateva, T. F., Moore, E. R. B., Abraham, W.-R., Lünsdorf, H., Timmis, K. N., Yakimov, M. M. \& Golyshin, P. N. (2000). Ferroplasma acidiphilum gen. nov., sp. nov., an acidophilic, autotrophic, ferrous-ironoxidizing, cell-wall-lacking, mesophilic member of the Ferroplasmaceae fam. nov., comprising a distinct lineage of the Archaea. Int J Syst Evol Microbiol 50, 997-1006.

Guindon, S. \& Gascuel, O. (2003). A simple, fast, and accurate algorithm to estimate large phylogenies by maximum likelihood. Syst Biol 52, 696-704.

Guindon, S., Lethiec, F., Duroux, P. \& Gascuel, O. (2005). PHYML Online - a web server for fast maximum likelihood-based phylogenetic inference. Nucleic Acids Res 33, W557-W559.
Harmsen, H. J. M., Wildeboer-Veloo, A. C. M., Grijpstra, J., Knol, J., Degener, J. E. \& Welling, G. W. (2000). Development of $16 \mathrm{~S}$ rRNAbased probes for the Coriobacterium group and the Atopobium cluster and their application for enumeration of Coriobacteriaceae in human feces from volunteers of different age groups. Appl Environ Microbiol 66, 4523-4527.

Holdeman, L. V., Cato, E. P. \& Moore, W. E. C. (1977). Anaerobe Laboratory Manual, 4th edn. Blacksburg, VA: Virginia Polytechnic Institute and State University.

Itoh, U., Sato, M., Tsuchiya, H. \& Namikawa, I. (1995). Cellular fatty acids and aldehydes of oral Eubacterium. FEMS Microbiol Lett 126, 69-74.

Jin, J. S., Zhao, Y. F., Nakamura, N., Akao, T., Kakiuchi, N., Min, B. S. \& Hattori, M. (2007). Enantioselective dehydroxylation of enterodiol and enterolactone precursors by human intestinal bacteria. Biol Pharm Bull 30, 2113-2119.

Jukes, T. H. \& Cantor, C. R. (1969). Evolution of protein molecules. In Mammalian Protein Metabolism, vol. 3, pp. 21-132. Edited by H. N. Munro. New York: Academic Press.

Kageyama, A. \& Benno, Y. (2000). Emendation of genus Collinsella and proposal of Collinsella stercoris sp. nov. and Collinsella intestinalis sp. nov. Int J Syst Evol Microbiol 50, 1767-1774.

Kageyama, A., Benno, Y. \& Nakase, T. (1999a). Phylogenetic and phenotypic evidence for the transfer of Eubacterium aerofaciens to the genus Collinsella as Collinsella aerofaciens gen. nov., comb. nov. Int $J$ Syst Bacteriol 49, 557-565.

Kageyama, A., Benno, Y. \& Nakase, T. (1999b). Phylogenetic evidence for the transfer of Eubacterium lentum to the genus Eggerthella as Eggerthella lenta gen. nov., comb. nov. Int J Syst Bacteriol 49, 1725-1732.

Kageyama, A., Benno, Y. \& Nakase, T. (1999c). Phylogenic and phenotypic evidence for the transfer of Eubacterium fossor to the genus Atopobium as Atopobium fossor comb. nov. Microbiol Immunol 43, 389-395.

Kanz, C., Aldebert, P., Althorpe, N., Baker, W., Baldwin, A., Bates, K., Browne, P., van den Broek, A., Castro, M. \& other authors (2005). The EMBL nucleotide sequence database. Nucleic Acids Res 33, D29D33.

Labrenz, M., Collins, M. D., Lawson, P. A., Tindall, B. J., Braker, G. \& Hirsch, P. (1998). Antarctobacter heliothermus gen. nov., sp. nov., a budding bacterium from hypersaline and heliothermal Ekho Lake. Int J Syst Bacteriol 48, 1363-1372.

Landais, C., Doudier, B., Imbert, G., Fenollar, F. \& Brouqui, P. (2007). Application of rrs gene sequencing to elucidate the clinical significance of Eggerthella lenta infection. J Clin Microbiol 45, 10631065.

Lane, D. J. (1991). 16S/23S rRNA sequencing. In Nucleic Acid Techniques in Bacterial Systematics, pp. 115-175. Edited by E. Stackebrandt \& M. Goodfellow. Chichester: Wiley.

Lau, S. K., Woo, P. C., Fung, A. M., Chan, K. M., Woo, G. K. \& Yuen, K. Y. (2004a). Anaerobic, non-sporulating, Gram-positive bacilli bacteraemia characterized by $16 \mathrm{~S}$ rRNA gene sequencing. J Med Microbiol 53, 1247-1253.

Lau, S. K., Woo, P. C., Woo, G. K., Fung, A. M., Wong, M. K., Chan, K. M., Tam, D. M. \& Yuen, K. Y. (2004b). Eggerthella hongkongensis sp. nov. and Eggerthella sinensis sp. nov., two novel Eggerthella species, account for half of the cases of Eggerthella bacteraemia. Diagn Microbiol Infect Dis 49, 255-263.

Lau, S. K., Woo, P. C., Woo, G. K., Fung, A. M., Wong, M. K., Chan, K. M., Tam, D. M. \& Yuen, K. Y. (2006). Eggerthella hongkongensis sp. nov. In List of New Names and New Combinations Previously 
Effectively, but not Validly, Published. Validation List no. 111. Int J Syst Evol Microbiol 56, 2025-2027.

Lawson, P. A., Greetham, H. L., Gibson, G. R., Giffard, C., Falsen, E. \& Collins, M. D. (2005). Slackia faecicanis sp. nov., isolated from canine faeces. Int J Syst Evol Microbiol 55, 1243-1246.

Maruo, T., Sakamoto, M., Ito, C., Toda, T. \& Benno, Y. (2008). Adlercreutzia equolifaciens gen. nov., sp. nov., an equol-producing bacterium isolated from human faeces, and emended description of the genus Eggerthella. Int J Syst Evol Microbiol 58, 1221-1227.

McCarthy, A. J. \& Cross, T. (1984). A taxonomic study of Thermomonospora and other monosporic actinomycetes. J Gen Microbiol 130, 5-25.

Mesbah, M., Premachandran, U. \& Whitman, W. B. (1989). Precise measurement of the $\mathrm{G}+\mathrm{C}$ content of deoxyribonucleic acid by highperformance liquid chromatography. Int J Syst Bacteriol 39, 159-167.

Minamida, K., Ota, K., Nishimukai, M., Tanaka, M., Abe, A., Sone, T., Tomita, F., Hara, H. \& Asano, K. (2008). Asaccharobacter celatus gen. nov., sp. nov., isolated from rat caecum. Int J Syst Evol Microbiol 58, 1238-1240.

Moore, W. E. C., Cato, E. P. \& Holdeman, L. V. (1971). Eubacterium lentum (Eggerth) Prevot 1938: emendation of description and designation of the neotype strain. Int J Syst Bacteriol 21, 299-303.

Moss, C. W., Kai, A., Lambert, M. A. \& Patton, C. (1984). Isoprenoid quinone content and cellular fatty acid composition of Campylobacter species. J Clin Microbiol 19, 772-776.

Mullis, K. B. \& Faloona, F. A. (1987). Specific synthesis of DNA in vitro via a polymerase-catalyzed chain reaction. Methods Enzymol 155, 335-350.

Nakazawa, F. \& Hoshino, E. (2004). DNA-DNA relatedness and phylogenetic positions of Slackia exigua, Slackia heliotrinireducens, Eggerthella lenta, and other related bacteria. Oral Microbiol Immunol 19, 343-346.

Nakazawa, F., Poco, S. E., Ikeda, T., Sato, M., Kalfas, S., Sundqvist, G. \& Hoshino, H. (1999). Cryptobacterium curtum gen. nov., sp. nov., a new genus of Gram-positive anaerobic rod isolated from human oral cavities. Int J Syst Bacteriol 49, 1193-1200.

Rodriguez Jovita, M., Collins, M. D., Sjödén, B. \& Falsen, E. (1999). Characterization of a novel Atopobium isolate from the human vagina: description of Atopobium vaginae sp. nov. Int J Syst Bacteriol 49, 1573-1576.

Rzhetsky, A. \& Nei, M. (1992). A simple method for estimating and testing minimum evolution trees. Mol Biol Evol 9, 945-967.

Schoefer, L., Braune, A. \& Blaut, M. (2001). A fluorescence quenching test for the detection of flavonoid transformation. FEMS Microbiol Lett 204, 277-280.

Skerman, V. B. D., McGowan, V. \& Sneath, P. H. A. (editors) (1980). Approved lists of bacterial names. Int J Syst Bacteriol 30, 225-420.
Skerman, V. B. D., McGowan, V. \& Sneath, P. H. A. (editors) (1989). Approved Lists of Bacterial Names (Amended Edition). Washington, DC: American Society for Microbiology.

Stackebrandt, E., Sproer, C., Rainey, F. A., Burghardt, J., Päuker, O. \& Hippe, H. (1997). Phylogenetic analysis of the genus Desulfotomaculum: evidence for the misclassification of Desulfotomaculum guttoideum and description of Desulfotomaculum orientis as Desulfosporosinus orientis gen. nov., comb. nov. Int J Syst Bacteriol 47, 1134-1139.

Tamura, K., Dudley, J., Nei, M. \& Kumar, S. (2007). MEGA4: molecular evolutionary genetics analysis (MEGA) software version 4.0. Mol Biol Evol 24, 1596-1599.

Thompson, J. D., Higgins, D. G. \& Gibson, T. J. (1994). CLUSTAL W: improving the sensitivity of progressive multiple sequence alignment through sequence weighting, position-specific gap penalties and weight matrix choice. Nucleic Acids Res 22, 4673-4680.

Tindall, B. J. (1990a). A comparative study of the lipid composition of Halobacterium saccharovorum from various sources. Syst Appl Microbiol 13, 128-130.

Tindall, B. J. (1990b). Lipid composition of Halobacterium lacusprofundi. FEMS Microbiol Lett 66, 199-202.

Uematsu, H., Sato, N., Djais, A. \& Hoshino, E. (2006). Degradation of arginine by Slackia exigua ATCC 700122 and Cryptobacterium curtum ATCC 700683. Oral Microbiol Immunol 21, 381-384.

van Belkum, A., Sluijuter, M., de Groot, R., Verbrugh, H. \& Hermans, P. W. (1996). Novel BOX repeat PCR assay for high-resolution typing of Streptococcus pneumoniae strains. J Clin Microbiol 34, 1176-1179.

Verhulst, A., van Hespen, H., Symons, F. \& Eyssen, H. (1987). Systematic analysis of the long-chain components of Eubacterium lentum. J Gen Microbiol 133, 275-282.

Wade, W. G., Downes, J., Dymock, D., Hiom, S. J., Weightman, A. J., Dewhirst, F. E., Paster, B. J., Tzellas, N. \& Coleman, B. (1999). The family Coriobacteriaceae: reclassification of Eubacterium exiguum (Poco et al. 1996) and Peptostreptococcus heliotrinreducens (Lanigan 1976) as Slackia exigua gen. nov., comb. nov. and Slackia heliotrinireducens gen. nov., comb. nov., and Eubacterium lentum (Prevot 1938) as Eggerthella lenta gen. nov., comb. nov. Int J Syst Bacteriol 49, 595-600.

Yakimov, M. M., Golyshin, P. N., Lang, S., Moore, E. R. B., Abraham, W.-R., Lünsdorf, H. \& Timmis, K. N. (1998). Alcanivorax borkumensis gen. nov., sp. nov., a new, hydrocarbon-degrading and surfactantproducing marine bacterium. Int J Syst Bacteriol 48, 339-348.

Yarza, P., Richter, M., Peplies, J., Euzéby, J., Amann, R., Schleifer, K. H., Ludwig, W., Glöckner, F. O. \& Rosselló-Móra, R. (2008). The All-Species Living Tree project: a $16 \mathrm{~S}$ rRNA-based phylogenetic tree of all sequenced type strains. Syst Appl Microbiol 31, 241250 . 